\title{
DEBATE: ¿QUÉ SIGNIFICÓ EL TRIUNFO DE ALLENDE PARA EL MUNDO? MIRADAS DESDE LA CULTURA
}

Carmen Castillo Echeverria, Costa-Gavras, Miguel Littin Cucumides, Ennio Vivaldi Véjar y Faride Zerán Chelech 


\section{DEBATE: ¿QUÉ SIGNIFICÓ EL TRIUNFO DE ALLENDE PARA EL MUNDO? MIRADAS DESDE LA CULTURA ${ }^{1}$}

Carmen Castillo Echeverría, Costa-Gavras, Miguel Littín Cucumides y Ennio Vivaldi Véjar

Modera: Faride Zerán Chelech

Jennifer Abate: quisiera darles una cordial bienvenida al conversatorio "¿Qué significó el triunfo de Salvador Allende para el mundo? Miradas desde la cultura", organizado por la Vicerrectoría de Extensión y Comunicaciones y auspiciado por la Revista Anales de la Universidad de Chile. Colabora en esta instancia la Fundación Víctor Jara. La conversación de hoy inaugura un ciclo dedicado a conmemorar y debatir en torno al triunfo histórico de Salvador Allende y el ascenso del gobierno de la Unidad Popular el 4 de septiembre de 1970. Agradecemos la presencia del rector de la Universidad de Chile, Ennio Vivaldi Véjar, y de los connotados invitados e invitada que nos acompañan: Costa Gavras, Carmen Castillo y Miguel Littín; bienvenidos y muchas gracias. La vicerrectora Faride Zerán los presentará al iniciar la conversación, pero antes quisiera darle la palabra al rector de la Universidad de Chile, doctor Ennio Vivaldi, quien encabezará esta actividad.

Ennio Vivaldi: muchas gracias, Jennifer. Un saludo muy afectuoso a Faride y a nuestros invitados, a quienes agradezco enormemente que estén aquí. Costa Gavras, Carmen Castillo y Miguel Littín, yo diría que ellos son protagonistas y representan los testimonios de una generación privilegiada por haber vivido un momento muy único en la historia de la humanidad y hacerlo desde Chile. Eso ha generado, en estos tres cineastas, algo muy extraordinario, que es la condición de haber sido testigos de un momento único y la necesidad de conocer, interpretar, compartir esa experiencia que quizás pocas generaciones han vivido con esa intensidad. Quisiera, en primer lugar, señalar algo muy especial de ese 4 de septiembre de 1970 . Me refiero a esa cosa fantástica, el hecho de que los chilenos podíamos elegir, así lo creíamos, entre tres conceptos de sociedad totalmente distintos, y los tres eran perfectamente factibles y posibles. Me refiero a los modelos que ofrecían Salvador Allende, Radomiro Tomic y Jorge Alessandri.

1. Este debate se realizó el viernes 4 de septiembre de 2020, a través de una transmisión en línea de la Vicerrectoría de Extensión y Comunicaciones de la Universidad de Chile. 
Hay que entender que estas tres candidaturas venían después de muchos, muchos años de organización obrera, del pensamiento socialcristiano, del pensamiento más tradicional en Chile. Esas tres candidaturas que se encuentran ese 4 de septiembre marcan muy profundamente, con una emoción indeleble, a los chilenos; yo podría escuchar mil veces el discurso de Salvador Allende, me emociona hasta las lágrimas y de nuevo siento una emoción muy intensa. Agradezco, como a tantos otros, a estos tres cineastas que han sido capaces de tomar esa experiencia y compartirla con una ciudadanía, una población, con una humanidad muy numerosa, así que con mucha emoción agradezco a nombre de la Universidad de Chile a estos tres visitantes, a quienes estamos ansiosos por escuchar. Gracias.

Jennifer Abate: muchas gracias, rector. Le dejo la palabra a Faride Zerán, Premio Nacional de Periodismo y vicerrectora de Extensión y Comunicaciones de la Universidad de Chile, con una dilatada trayectoria como periodista cultural, directora y fundadora de medios de comunicación como la revista Rocinante. Ha publicado, entre otros, los libros Tejado de vidrio, crónicas del malestar, Carmen Waugh, la vida por el arte; Chile actual: crisis y debates desde las izquierdas; Mayo feminista: la rebelión contra el patriarcado y La guerrilla literaria: Huidobro, De Rocka, Neruda, por el que obtuvo el galardón del Consejo del Libro y la Cultura.

Faride Zerán: gracias, querida Jennifer; gracias, querido rector, por esas palabras. Vamos a presentar primero a nuestros queridos amigos e invitados en este día en que estamos conmemorando no solo los cincuenta años del triunfo de Salvador Allende, sino que también la figura de un hombre sin duda clave en la historia de nuestro país. Lo hacemos en medio de una pandemia y no podemos dejar de señalar ese hecho, porque lo hacemos en medio del dolor de centenares de miles de familias. En el caso chileno, la pandemia ya ha costado más de quince mil víctimas.

Voy a presentar a nuestros invitados especiales. Nos acompaña el director greco-francés Costa Gavras, uno de los autores que cultiva un cine crítico y político: Missing abordó la complicidad de Estados Unidos en el golpe de Estado de Augusto Pinochet; en Estado de sitio denunció la connivencia de la CIA con la dictadura cívico-militar en Uruguay; y en La confesión abordó las torturas del estalinismo. Denunció las buenas relaciones entre la Santa Sede y Hitler en Amén, las angustias de los emigrantes en Edén al Oeste y la voracidad de los banqueros en El capital. En definitiva, su trabajo es una crónica política que nos sigue interpelando hasta el día de hoy. La semana del cine de Valladolid en 2003 y el festival Lumière de Lyon en 2015 dedicaron a este director amplias retrospectivas. Entre sus premios se cuentan el Gran Premio del Jurado y la Palma de Oro del Festival de Cannes, el Óscar a la 
Mejor Película de Habla no Inglesa por Z, y el Óscar al Mejor Guion Adaptado por Missing.

Recibimos también a la documentalista Carmen Castillo, autora de casi una veintena de trabajos audiovisuales, entre ellos Calle Santa Fe (2007), seleccionada en la sección Un certain regard del Festival de Cannes, La flaca Alejandra (1994), Aún estamos vivos y La embajada, estrenada en 2019. También ha escrito los libros Un día de octubre y Santiago-París. El vuelo de la memoria. En 2019, la Cineteca Nacional le dedicó la retrospectiva "El cine de Carmen Castillo", en la que se hizo un repaso por su obra. Entre sus premios se cuentan el Gran Coral del Festival Internacional del Nuevo Cine Latinoamericano, el Premio Altazor de las Artes Nacionales en la categoría Artes Audiovisuales, Dirección Documental, y el Premio Especial en el Festival Internacional del Nuevo Cine Latinoamericano de La Habana.

Finalmente, agradecemos también la presencia del cineasta Miguel Littín. Director y académico del Instituto de Estudios Audiovisuales de la Universidad de O’Higgins, Miguel Littín tiene más de cincuenta años de carrera filmográfica y entre sus obras se encuentran algunos de los clásicos del cine chileno, como El Chacal de Nabueltoro, Actas de Marusia, Dawson, Isla 10 y Allende en su laberinto. Entre sus galardones se cuentan el Colón de Oro y el Colón de Plata al mejor director del Festival de Cine Iberoamericano de Huelva, el Premio Espacio Libre del Autor del Festival Internacional de Cine de Venecia y el India Catalina de Oro del Festival Internacional de Cine de Cartagena.

Es un amplio currículum, lleno de premios, el de estos tres creadores. Vamos a partir con una reflexión inicial de cinco minutos de cada uno de ustedes sobre lo que significó este hecho, porque septiembre es un mes muy significativo para nosotros. No solo es el mes de las Fiestas Patrias, sino que también recordamos el quiebre de la democracia, que marca no solo una tragedia de la cual aun no somos capaces de recuperarnos, sino que el fin del primer gobierno socialista que llegó al poder, una gesta que fue observada por nosotros y por todo el mundo. Partamos por los recuerdos del 4 de septiembre de 1970. ¿Qué significó esa fecha para cada uno de ustedes? ¿A qué memoria les remite este acontecimiento? Carmen, por favor, partamos con lo que significa este día, cuando Allende fue electo con el voto popular. ¿Qué te dice tu memoria política y emotiva de esa época?

Carmen Castillo: creo que recordar hoy, traer a la vida esa memoria que se mueve con uno desde hace cincuenta años, significa sentirnos menos solos, más fuertes; la "esperanza en el pasado", expresión paradójica que significa tal vez "no solo pensar el pasado sino dejarnos pensar por él”, es esencial para acompañarnos a la hora de dibujar el horizonte. En Salvador Allende, el hombre político, la voluntad vibraba más alta que las ideas. Allende era ante todo un hombre de corazón, para quien todo 
lo que esta palabra encierra — valor, rectitud, lealtad, emoción — contaba más que el resto. Ese músculo infatigable lo llevó a crear desde muy joven una línea política, un programa y, finalmente, un instrumento político, la UP, una alianza de partidos marxistas y cristianos socialistas que logró ganar las elecciones democráticamente. Desde la franja del MIR, desde los revolucionarios, nos dimos cuenta de qué manera era fundamental escuchar, acompañar al pueblo en esa aspiración. El pueblo quería a Salvador Allende como presidente de la república. Durante toda su vida politica se preocupó de educar, de crear un pueblo, fue un hombre político, que era lo contrario de un demagogo. Salvador Allende educó, acompañó y, cuando gana, ese día de tensiones y emociones fuertes, yo me encontraba en una de las mesas de votación. Desde el balcon de la FECH, recuerdo a Tati, Beatriz Allende y el pueblo reunido en la Alameda, la alegría, el clamor de la esperanza, el clamor de "ahí está nuestro presidente, ahí está nuestro compañero".

Creo que, entre la calle y el edificio de la FECH, escuchando el discurso de Salvador Allende, vivimos un momento en que no había distancia entre los de arriba y los de abajo, la voz de Allende, sus palabras, se deslizaban entre mujeres, niños, hombres, sus iguales, sus compañeros, era ese pueblo, el pueblo allendista que se constituía en ese momento como victorioso. Esa victoria, por supuesto, habían querido robarla, recordemos a Estados Unidos, la burguesía, la muerte de Schneider.

El 4 de septiembre marca, entonces, la victoria de un hombre y de un programa socialista. Desde esa comunidad de diferentes reunidos en ese momento, en la noche en que Salvador Allende se dirige al pueblo, se puede ya palpar, es tangible, que estamos asistiendo a un momento histórico en que por primera vez una alianza de partidos marxistas, un proyecto político claramente socialista, logra ganar democráticamente una elección presidencial. Un acontecimiento. Un imprevisble de la Historia. Es lo que debemos recordar hoy: nada está escrito de antemano, no existe la fatalidad en la historia. Salvador Allende ganó y nos vuelve a decir: "la historia la escribimos nosotros, la historia la escriben los pueblos". Es importante tener traer esa memoria a nuestro presente.

Faride Zerán: gracias, Carmen. Costa, ¿qué significó para ti ese 4 de septiembre? ¿Qué pensaste? ¿Qué te suscitó ese momento?

Costa Gavras: en Francia fue un golpe enorme, un terremoto, cómo era posible que, en América Latina, un demócrata arribara al poder, era una cosa imposible de pensar y un placer inmenso. Cuando llegué a Chile entendí por qué, porque encontré en Allende a un hombre extraordinario, de una generosidad grandísima, que explicaba exactamente lo que quería hacer con una precisión perfecta. Lo encontré tres veces y cada una es un momento imposible de olvidar, especialmente su amor 
por la democracia y su amor por el pueblo. En Europa hablaban de castrismo, de sovietisimo, nada que ver; había una libertad total, descubrí yo en Chile, sus palabras eran un acuerdo total con lo que hacía. Tuve la felicidad de ir con él al sur a las elecciones municipales en Temuco, vi a los mapuche gritando "iAllende, Allende!" con un amor extraordinario, fui a una mina de carbón con Alberto Jerez y era una experiencia única. Cuando llegué a Francia, hablé de todo eso, la gente no podía ver los periódicos, no sabían. Claro que la gente de izquierda hablaba muy positivamente, pero sin conocer la realidad chilena. Allende fue una persona única y me parece que es un ejemplo histórico para la izquierda por siempre, por eso tengo una admiración tremenda por ese hombre.

Faride Zerán: gracias, Costa. Miguel, ¿qué significa para ti la memoria de Allende? ¿Qué te evoca tu memoria afectiva?

Miguel Littín: saludo a todos con mucho afecto, a Carmen, a Costa, al rector, a ti. Fue verdaderamente una conmoción. Lo que dice Costa: un terremoto emocional muy fuerte. El triunfo de Allende nos cambió la vida, significaba que Chile entraba a la historia moderna, a la historia del mundo, y significaba el cumplimiento de tantos anhelos, de la educación, el trabajo, la cultura. En el mundo cultural que estaba con Allende fue una explosión espontánea, todo el mundo pintaba, cantaba, una alegría inconmensurable nunca más vivida. Recuerdo que el día 4 de septiembre fue de gran serenidad, tranquilidad, la gente fue a votar con una disciplina que es muy habitual en los chilenos, como cumpliendo un rito sagrado, en silencio. Recorrimos las mesas de mujeres, de hombres, nosotros estábamos en el Canal 9 de la Universidad de Chile, que fue muy importante en este hito de Salvador Allende, porque estaba tomado por los trabajadores, docentes, y era donde Allende había hecho su campaña. Quiero decir, algo importante desde el punto de vista de los recuerdos. En un momento, a las seis de la tarde, cuando los votos daban la tendencia de que Allende podía ganar, no había nadie de la UP en ninguna parte, nadie llegaba a decir "ganamos", nadie llegaba a decir algo y estábamos desesperados, pero sobre todo porque nuestra mesa de cómputo oficial empezó a dar como ganador a Alessandri por la misma cantidad de votos que ganaba Allende. Llegó Bernardo Leighton, diputado de la DC, a quien llamábamos "hermano Bernardo", y nos dice: “¿qué pasa con ustedes? ¿Por qué está ganando Alessandri si el que gana es Salvador?”. Y nos quedamos mudos, porque no sabíamos qué hacer, y en un momento el jefe de prensa del canal, que era Augusto Olivares, gran amigo de Allende, además de uno de sus principales colaboradores, entró y siguió insistiendo en que ganaba Alessandri. Entró a la sala de prensa y lo encerramos con llave. Entramos al estudio y yo, que era el director y productor del Canal 9, y los trabajadores dijimos: "desde este momento gana 
Allende". El hermano Bernardo Leighton insistía por detrás: "sí, ganó Salvador”, y empezamos a trasmitir. En ese momento entró una persona al canal con una radio a pilas en que se estaba trasmitiendo el famoso discurso desde los balcones de la FECH, y todas las cámaras empezaron a irse hacia la radio y empezamos a improvisar un programa del triunfo porque, claro, no teníamos móvil, y entiendo que mi amigo Sergio Trabucco, cineasta, corrió con una de las cámaras hasta la FECH y es el único testimonio en imagen que existe de ese discurso. Era tal la euforia, que logramos coordinar un programa extraordinario. Dicho esto, Allende ha sido la figura más fundamental e importante que ha pasado por mi vida.

Faride Zerán: gran recuerdo, Miguel. Ennio, ¿qué significó para un estudiante de Medicina el triunfo de Salvador Allende?

Ennio Vivaldi: qué lindo escuchar a Miguel, porque nosotros, como estudiantes, teníamos distintas tareas, los jóvenes allendistas. Tengo nítidos los recuerdos de que, si el canal de la Chile estaba dando como ganador a Alessandri, el otro canal, que era alessandrista, estaba dando como ganador a Allende, así que estábamos compensando las dos cosas. Creo que, como nunca, había una sensación que no es fácil para los seres humanos en la historia, en general, que es sentir una emoción que trascendía lo personal, lo individual, se generaba un ambiente. Recuerdo que llegué caminando a la FECH desde donde estábamos como estudiantes, se había terminado el discurso de Allende. La sensación era que ya no existían los límites habituales de los intereses personales, individuales, que se compartía, que había comunicación con el resto de la población con la que íbamos caminando. Éramos jóvenes que teníamos toda la vida por delante en esta sociedad tan marcada por la pobreza, las desigualdades. Era una sensación muy única y es muy importante tener eso presente y reflexionar sobre las múltiples circunstancias que impidieron que ese proyecto se desarrollara. No es cuestión de decir que el mundo estaba bastamente polarizado y, por lo tanto, no cabían excepcionalidades como la que ocurría en Chile, sino que es muy importante una reflexión sobre qué pasó al interior de los movimientos que uno esperaba que apoyaran al presidente, y eso tuvo debilidades importantes que facilitaron que esta experiencia no fuera única. Me quedo con lo que han dicho los tres: la emoción única que fue para los jóvenes, los jóvenes estudiantes de la Universidad de Chile.

Faride Zerán: gracias, Ennio. Todos conocieron a Allende y quisiera que lo describieran. Carmen, ¿cómo lo retratarías tú? Por otro lado, quiero que desarrollen los factores que gatillaron tanto interés internacional por Salvador Allende. ¿Por qué los ojos del mundo se volcaron sobre Chile? 
Carmen Castillo: lo que me parece fundamental recordar es que Salvador Allende era un caballero. Un caballero de la esperanza. Era un hombre que llevaba sobre sí muchas derrotas, perdió muchas batallas electorales antes de ese 4 de septiembre de 1970. Entre testimonios leídos y vivencias, recordar esa actitud íntimamente victoriosa frente a esos momentos. El 64, muchas mujeres allendistas lloraban, derrumbe, Allende sonriendo, levantándole el ánimo a cada uno, "la próxima, ganamos". Hay que pensar a Allende no solo como su línea política, sino también comprender que ese hombre era amistad, afecto, fidelidad, ética, valores, como yo decía antes; un hombre de corazón. Tuve el privilegio de trabajar junto a él con Beatriz Allende, era un hombre múltiple, capaz de interesarse en el más mínimo acto que hubiera que realizar en cualquier lugar, pueblito de Chile. Recordemos el Tren de la Victoria deteniéndose de pueblo en pueblo, un abrazo, una palabra a cada persona, por eso finalmente, creo, gana Allende años después. Hoy habría que ir nuevamente pueblo por pueblo, estación de tren por estación de tren —es una metáfora, por supuesto- hablando, conversando. Él fue un educador y a nosotros, que convivimos momentos a veces muy tensos, difíciles, otros muy alegres, siempre nos sorprendía esa manera repleta de humor, repleta de consideraciones que tenía para discutir con algunos que queríamos acelerar más.

Allende poseía también un cariño, una lealtad por los movimientos revolucionarios, por Cuba, y eso no hay que olvidarlo nunca, porque le da mayor grandeza todavía a lo que era su visión política para Chile, su programa. Allende creía en el sufragio universal, lo defendió y después se va a inmolar en esa línea, por la democracia que está defendiendo. Lo que Salvador Allende nos entregó como hombre, político, soñador, es de toda vigencia.

Faride Zerán: es una lástima que hoy no queden trenes ni estaciones de trenes. Costa, pienso en la alusión de Carmen a los movimientos revolucionarios y en la famosa película Compañero presidente que filma Miguel. En un momento se iba a exhibir La confesión en Chile, que es una denuncia y crítica a los crímenes del estalinismo, y de pronto se dice que la película no se puede dar en Chile porque intentan censurarla. ¿Qué pasa ahí, a propósito de esa libertad y espíritu de Allende?

Costa Gavras: me llamaron para decirme que los socialistas, que Allende, prohibía la película en Chile. Llamé a los productores americanos, a la Paramount. Entonces me llamó Augusto Olivares, que es un personaje extraordinario, que realmente era un personaje de una fuerza y convicción profunda y ha llegado a ser mi amigo por siempre. Augusto me dijo: "vamos a ver a Allende". Y Allende me dice que no hay ninguna prohibición, que los cineastas hablan lo que quieran. Insistió mucho en que no sería prohibida. 
Entre los colaboradores de Allende había un amor, una admiración para seguir a este hombre, que era muy particular. ¿Por qué particular? Porque hicieron posible que un hombre de izquierda llegara al poder, una simple persona, un doctor, no un jefe. La segunda vez que lo vi llegué a decirle adiós y a agradecerle, y me invitó al sur, a Temuco. Lo que recuerdo es cómo los mapuche miraban a Allende, con fotos y esperanza en que en el futuro podía cambiar su vida, una vida aparentemente muy difícil y complicada. Siempre lo vi con esa voluntad de ir hacia adelante. Muchos años después, supe, por un amigo de Argelia, que cuando ocurrió el golpe, el presidente de Argelia llamó a Allende para decirle que podía vivir en su país, y que él dijo: "no, yo me quedo con mi pueblo hasta el final".

Faride Zerán: gracias, Costa. Miguel, tú fuiste gerente de Chilefilms, la empresa cinematográfica del Estado, tuviste contacto estrecho con Allende. ¿Qué destacarías del presidente? Pregunto esto porque hay generaciones que no lo conocieron, que solo se han aproximado por los textos. ¿Quién era este personaje?

Miguel Littín: bueno, su tremenda personalidad, su seguridad en el proyecto político que encabezaba. Él había contribuido a la izquierda chilena desde el año 52, 58, 64, había recorrido todo Chile, había estado en todos los hogares, de modo que la gente lo percibía como una persona de su familia, era un hombre muy, muy cercano, y el movimiento de la UP y de los frentes populares no se pueden entender sin la personalidad de Salvador Allende, con todas sus grandezas y todas sus falencias, pero ahí estaba Allende construyéndolo. Una de las cosas que más me impresionó, tomando en cuenta la gran personalidad del líder, era su gran afecto, su ternura personal. Recuerdo que después de una reunión en su casa, en Guardia Vieja, antes de los programas de televisión donde yo era su asesor y de Augusto Olivares, que era su gran amigo, y también estaba José Tohá, ellos se retiraron y quedé solo con Allende. De pronto, él se alejó de mí, fue al ventanal y dijo esta frase: "la Tencha está bien, la familia está bien, vamos a ganar, compañeros”. No recuerdo nada más, pero como soy un hombre de cine e imágenes, eso me caló profundamente; era un monólogo consigo mismo y estaba hablándole a su propia historia. Eso me hace entender la coherencia permanente, el sentido de la amistad, de los afectos y la lealtad consigo mismo y su programa. Tengo muchos otros recuerdos, me cuesta elegir uno solo. Si me permiten, uno que fue decisivo: estaba en Guardia Vieja y le dicen que tienen que anunciarle algo de la más alta importancia. Rápidamente, se organiza un pequeño lugar, un sillón para él, una especie de sofá para los dirigentes de la UP. Viene Volodia, Alberto Jerez, la senadora Campusano, etcétera; se sientan al frente y nosotros, que estábamos trabajando ahí con Allende, empezamos a servir como parte de la casa. Él les pregunta a qué se debe la visita y alguien dice, después 
de mucha dificultad, en un momento bastante dramático, diría yo: "mire, Salvador, nosotros reconocemos su trayectoria, pero pensamos que usted no va a ser el candidato de la UP. Ha pasado el tiempo y usted es una figura gastada". Yo estaba al lado de él, me mira y dice: "si estoy gastado, cambiaré, entonces". Y luego dice: "mire, ustedes vayan y díganle a los compañeros y partidos de la UP que Allende va a ser el candidato y Allende va a ser el presidente de Chile. Muchas gracias". Esos momentos se me quedaron grabados porque él los tomaba con mucho humor y los comentaba, pero no delante de la gente, porque era muy caballero y respetuoso.

Faride Zerán: Miguel, tú te haces cargo de este dialogo de Allende con Régis Debray, que también tiene que ver con el impacto que produce en el mundo la figura de Salvador Allende. ¿Por qué era tan seguido desde fuera todo el proceso de la UP?

Miguel Littín: porque era inédito que un presidente marxista y revolucionario instalara una revolución con libertad de expresión, con respeto a los poderes públicos, a la institución, al oponente, una revolución, como él lo dijo, "con empanadas y vino tinto", una vía chilena al socialismo. Él se lo dice a Régis en un momento: "mira, nosotros estamos instaurando una revolución diferente, una revolución acorde con lo que es la historia de Chile, con lo que es su tradición". Y, por ejemplo, cuando fuimos a Columbia con Orlando Letelier a mostrar Compañero presidente, cuando entramos, multitudes de estudiantes gritaban “¡Allende, Allende!”. Era impresionante, y eso ocurría en Estados Unidos, en Argentina y en Uruguay, y las discusiones con los compañeros después de ver la película eran larguísimas y enjundiosas, les llamaba la atención la personalidad de esta persona y tratar de explicar las cosas inexplicables, que hubiera un gobierno de izquierda sin suprimir libertades o un hombre con una solidaridad tan grande con todos los movimientos revolucionarios, pero que, sin embargo, tenía un camino propio que señalaba, además, grandes posibilidades al resto del mundo para hacer una revolución de ese tipo.

Faride Zerán: Ennio, la misma pregunta: ¿cuál crees que fue el impacto de Allende afuera? Antes, quiero decir una cosa: no puedo no consignar, a propósito de las libertades de esos tres años, que, siendo periodista en Chile Hoy, hasta el día del golpe nunca vi un gesto de censura. Eso es muy importante para las nuevas generaciones. Fue una gran lección.

Ennio Vivaldi: ha sido un privilegio estar con Costa, con Carmen, contigo, Faride, y con Miguel. Quiero hacer dos reflexiones, escuché muy emocionado lo que aquí 
se dijo y quisiera tomar algunas palabras de Carmen y también de Costa y de Miguel. Lo primero es la fortuna del triunfo. Muchas veces, los contestatarios casi parten de la base de una derrota inevitable; es tan fuerte el enemigo. Pero en Allende era tan grande esa absoluta convicción de que no solamente debíamos, moralmente, ganar, sino que íbamos a ganar de verdad. Lo otro es una cosa de la que me he dado cuenta y que confieso que muy tardíamente se me viene a la mente. Pensando en la trascendencia internacional, el discurso de despedida es uno que no se puede escuchar sin emoción, pues va a pasar a la historia como uno de los discursos políticos más importantes que haya dicho cualquier mandatario en el mundo. Ahí hay una cosa que es notable, notable, como trataba de sugerir yo antes. Era tan obvio que dentro de su propio campo había mucha incomprensión — mucha irresponsabilidad, sería una palabra adecuada-, pero en su discurso final no tiene una palabra de reproche hacia su propia gente, y creo que eso le otorga una grandeza impresionante, pues mantiene una lealtad y un cuidado hasta el último momento hacia el pueblo que lo apoyó, y pretendía que sufriera lo menos posible. Ese mensaje a su propia gente de Salvador Allende es notable. Muchas gracias, Costa, Carmen, Miguel; es un honor para la Universidad de Chile contar con ustedes.

Faride Zerán: gracias, Ennio. Lo último que les quiero pedir es una reflexión: ¿cuál creen que es llegado que deja Salvador Allende cincuenta años después?

Costa Gavras: se ve muy claro en la película que hizo Miguel con Debray: Allende habló de una revolución completamente distinta de la idea de Revolución Francesa, por ejemplo. Debray ve que no hay otra posibilidad de llegar al poder, de conducir al pueblo a una revolución verdadera. Nadie pensaba que era posible lograrlo, pero él mostró que había otro tipo de revolución, una revolución verdadera en la que yo creo mucho.

Faride Zerán: gracias, Costa. Miguel, ¿cuál crees tú que es el legado de Allende cincuenta años después? Sabemos muy bien cómo Allende fue negado en la transición a la democracia.

Miguel Littín: que la revolución es con democracia, que es imposible hacer una revolución sin democracia, libertad de expresión y esos valores que son consustanciales a la vida democrática. También, que el valor del individuo es tan importante como el valor de lo colectivo, que no se puede olvidar el valor del individuo o poner el valor o la libertad individual en relación con la libertad colectiva, que ambas cosas deben conjugarse. Creo que el proyecto de Allende sigue siendo válido y un legado importante y que podemos refundar, sin lugar a dudas, el 
25 de octubre en el plebiscito que se va a desarrollar en Chile, llevando adelante el Apruebo y la convicción de que hay que vencer con justicia, igualdad y equilibrio.

Faride Zerán: gracias, Miguel. Carmen, tu reflexión final: ¿qué énfasis señalarías en cuanto a su legado?

Carmen Castillo: Allende y la UP eran afines al proyecto de Mitterrand, por lo tanto, se explica la solidaridad del pueblo francés con la lucha de resistencia a Pinochet. Su solidaridad. Mitterrand, como presidente, apoyó la resistencia clandestina y abierta contra Pinochet. Mitterrand había visitado Chile antes de ser electo y conversó personalmente con Allende. Un diálogo que él recordó muchas veces. El impacto internacional de Salvador Allende y de su gobierno fue enorme.

Creo que debemos rescatar el pensamiento politico, la trayectoria, los valores, la ética de Salvador Allende. Más allá de su muerte, de aquella fotografía de su cadáver, llenar el vacío, darles movimiento a las estatuas, recrear el relato de esa vida desde el hoy, recoger la promesa de una sociedad de justicia y verdadera libertad que su muerte dejó incumplida. Estudiar. Ese legado de Allende está presente desde la rebelión popular de octubre, bastaba recorrer asambleas, debates, para saber que el espíritu de Salvador Allende, el espíritu de nuestros muertos, de Miguel y de otros, estaba allí presente. ¿Qué significa recordar a Allende? Significa que debemos llenarlo de vida, no como héroe, sino recordar, como esta tarde, al hombre. Cómo lo vivimos y recordamos cada uno, la creatividad en un contexto de lucha de clases, porque, ¿qué sucedió en Chile? En Chile hubo un pueblo victorioso, sucedió que la igualdad se vivía, se tenía conciencia de ella, la igualdad se activó y se ejerció todos los días, pero frente a nosotros se levantó el odio a la igualdad, la masacre, la muerte. Hasta el día de hoy en este planeta dominado por el fascismo económico. Walter Benjamin, antes de morir, decía: "un fascista no es más que un liberal dispuesto a llegar a las últimas consecuencias". Yo diría: "un neofascista no es otra cosa que un neoliberal dispuesto a llegar hasta el final, a destruir nuestra sociedad, nuestro planeta". Allende nos recuerda que es posible ganar, que la fraternidad, el afecto, la educación, estar del lado de los oprimidos sin nunca claudicar de esa posición es lo que nos llevará a vivir con la esperanza entre los dientes. Nuestros recuerdos deben constituirse en un pasado activo con el cual inventaremos el futuro. Hay urgencia.

Faride Zerán: gracias, Carmen. 